\title{
Treatment of Severe Hypertriglyceridemia with Continuous Insulin Infusion
}

\author{
Yesica Rodríguez Santana, Andrea Nimo Román, Iker García Sáez, \\ José Manuel López Alvarez, Eduardo Consuegra Llapur, and Rafael González Jorge
}

Pediatric Intensive Care Unit, Hospital Universitario Materno-Infantil, 35016 Las Palmas de Gran Canaria, Spain

Correspondence should be addressed to Eduardo Consuegra Llapur, ed60hab@gmail.com

Received 11 May 2011; Accepted 5 June 2011

Academic Editors: M. Egi and C. D. Roosens

Copyright (C) 2011 Yesica Rodríguez Santana et al. This is an open access article distributed under the Creative Commons Attribution License, which permits unrestricted use, distribution, and reproduction in any medium, provided the original work is properly cited.

\begin{abstract}
Severe hypertriglyceridemia $(\mathrm{SH})$ represents a therapeutic emergency because of the possibility of developing cardiovascular events and hyperlipemic acute pancreatitis (PA). Most patients with SH suffer primary or genetic abnormality in lipid metabolism in combination with a precipitating factor such as uncontrolled diabetes mellitus, alcoholism, and drug intake. The standard treatment of hypertriglyceridemia (HTG) with omega 3 fatty acids and fibrates, along with dietary changes, has no effect on an emergency situation. There are no clinical guidelines to SH, but therapy with insulin, heparin, a combination of both, plasmapheresis, or octreotide have been tested succesfully. We report the case of a 10-year-old girl with clinical acute pancreatitis and diabetic ketoacidosis debut, along with incidental finding of an $\mathrm{SH}$, who had a good outcome after treatment with insulin intravenous infusion.
\end{abstract}

\section{Case Report}

A ten-year-old girl previously healthy, except allergic rhinitis caused by mites at the age of three was admitted to Intensive Care Unit (ICU) because of abdominal pain, anorexia, polydipsia, vomiting, and hyperventilation. She was diagnosed with acute pancreatitis and diabetic ketoacidosis $[1,2]$.

On physical examination, she presents with (a) BP 115/74 mm Hg, HR $128 \mathrm{bpm}$, RR $23 \mathrm{rpm}$, Temp $37^{\circ} \mathrm{C}$, O2 Sat $98 \%$, (b) decay and signs of moderate-severe dehydration (pale skin, sunken eyes, oral mouth typically dry, and Kussmaul breathing), (c) normal cardiopulmonary auscultation, and (d) spontaneous abdominal pain that intensifies with palpation and hepatomegaly of $3 \mathrm{~cm}$ below costal margin.

Lab tests show a severe metabolic acidosis (venous gasometry: pH 6.76, pCO2 $7.3 \mathrm{~mm} \mathrm{Hg}$, HCO3 $1.3 \mathrm{mmol} / \mathrm{L}, \mathrm{BE}$ $-31 \mathrm{mmol} / \mathrm{L}$ ), glucose $472 \mathrm{mg} / \mathrm{dL}$, amylase $700 \mathrm{U} / \mathrm{L}$, alkaline phosphatase $100 \mathrm{U} / \mathrm{L}$, and LDH $280 \mathrm{U} / \mathrm{L}$. In Chest-abdomen $\mathrm{X}$-ray, a gastric dilatation is evident, with no other findings. ECG: incomplete right bundle branch block without signs of myocardial ischemia. Abdominal ultrasound shows signs of liver disease and/or fatty liver. Abdominal CT: moderate amount of free abdominal fluid. No objective findings of liver or pancreatic involvement were observed.

Acute pancreatitis was treated with fasting, gastric decompression by nasogastric tube, and analgesia with meperidine and IV magnesic metamizole. Fluid therapy was also initiated and intravenous bicarbonate. In addition, we started insulin continuous perfusion for diabetic ketoacidosis treatment [2-5].

Due to the lipemic appearance of serum (Figure 1), we performed a lipid profile, showing high levels of triglycerides (TGC) 10,260 mg/dL and total cholesterol $970 \mathrm{mg} / \mathrm{dL}$ (nonHDL $924 \mathrm{mg} / \mathrm{dL}$ ). By the finding of an SH, we consider emergency therapeutic options (plasmapheresis, intravenous infusion of heparin, and/or insulin) and we chose the latter.

During the first 24 hours, vascular expansion and dopamine support $(10 \mathrm{mcg} / \mathrm{kg} / \mathrm{h})$ due to sustained hypotension was required. A progressive normalization of blood glucose, acidosis, and ketonuria was achieved. Triglyceride levels decreased progressively so insulin infusion remained at 0.5 to $1 \mathrm{IU} / \mathrm{kg} / \mathrm{h}$ and supply of glucose controlled. At 48 hours, TGC levels dropped to $6174 \mathrm{mg} / \mathrm{dL}$, decreasing to $476 \mathrm{mg} / \mathrm{dLs}$ at 96 hours (Figures 2 and 3). During her stay in ICU, 


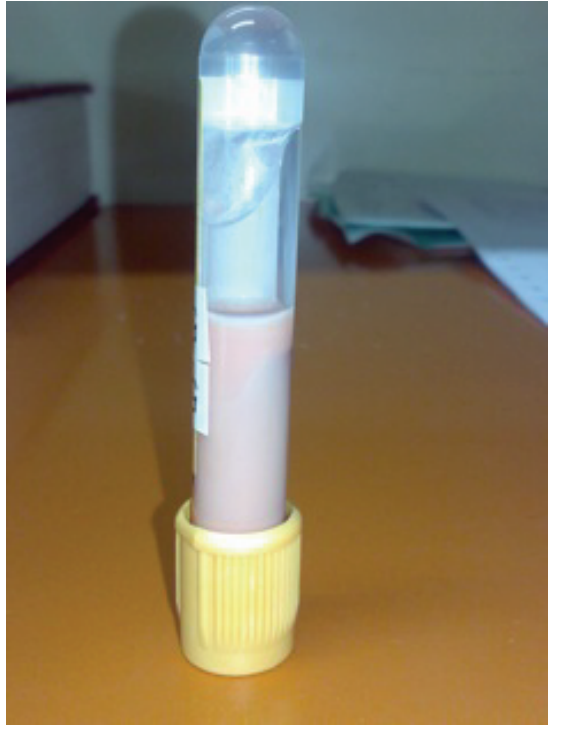

FIGURe 1: Patient's hyperlipemic serum.

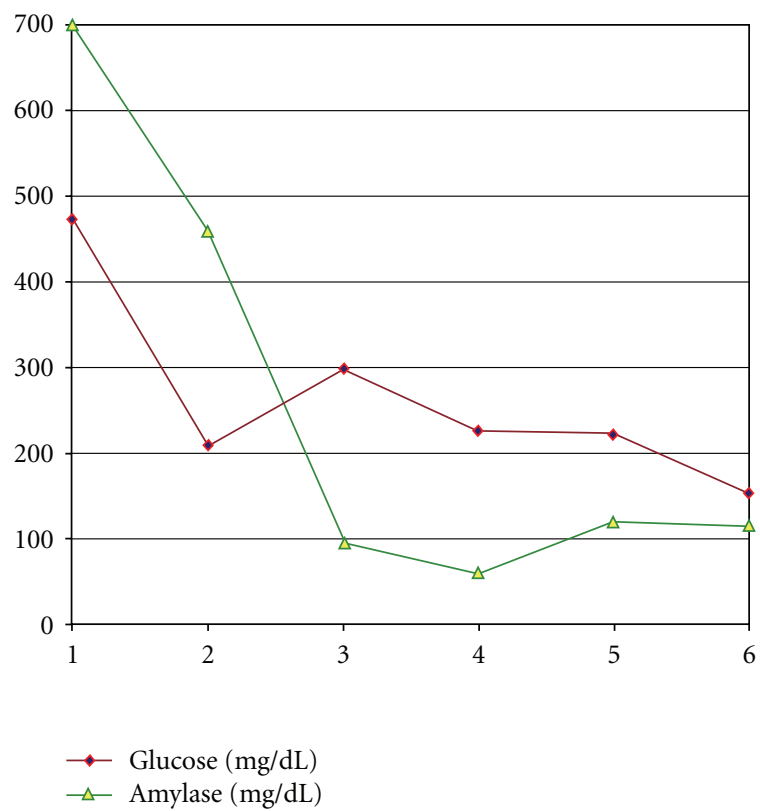

Figure 2: Daily evolution of glucose and amylase levels during the first six hospitalization days.

there were no neurological disorders, respiratory or kidney problems, and she did not experience abdominal pain after discontinuation of analgesia within 24 hours after admission. There were no bleeding and no clinical or laboratory signs of infection. About 48 hours after admission, we started lipidfree parenteral nutrition. She was discharged from the ICU after 72 hours, following clinical stabilization in pediatric ward where she remained hospitalized 2 weeks.

After two months of monitoring, clinical evolution was found favorable. Asymptomatic, TGC level was $82 \mathrm{mg} / \mathrm{dL}$, total cholesterol $173 \mathrm{mg} / \mathrm{dL}$ (HDL $41 \mathrm{mg} / \mathrm{dL}$ and LDL $116 \mathrm{mg} / \mathrm{dL}$ ), amylase $61 \mathrm{U} / \mathrm{L}$, lipase $12 \mathrm{U} / \mathrm{L}$ (both normal).

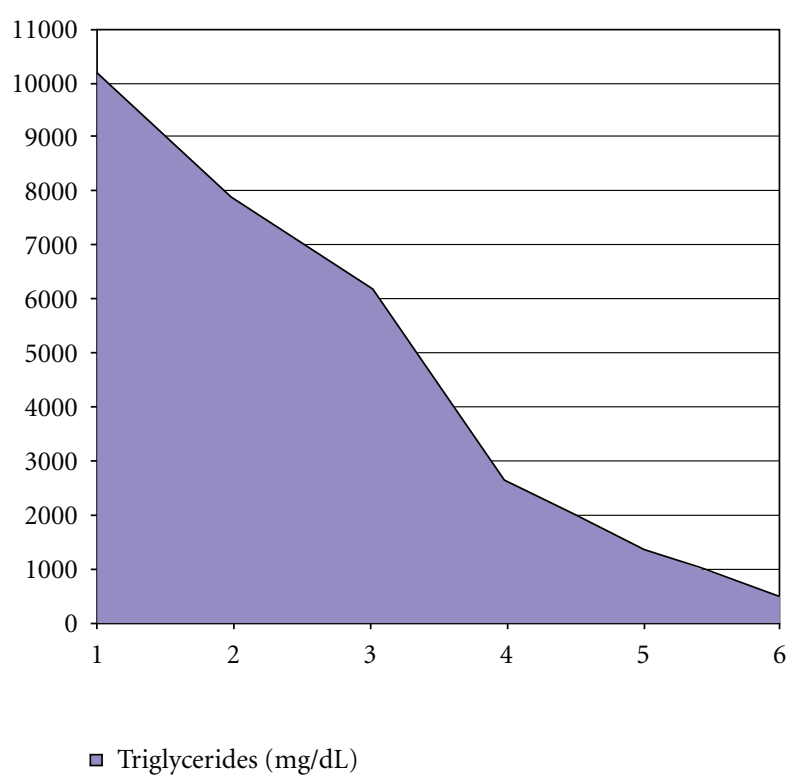

FIGURE 3: Serum triglycerides levels during the first six hospitalization days.

ALT, AST, and GGT were also normal. Lipoprotein determinations were Al: $25 \mathrm{mg} / \mathrm{dL}(115-210 \mathrm{mg} / \mathrm{dl}), \mathrm{B}: 62 \mathrm{mg} / \mathrm{dL}$ (55-135 mg/dL) B/A1 Ratio: $2.48 \mathrm{mg} / \mathrm{dL}$, E: $614 \mathrm{mg} / \mathrm{dL}(0-$ 94), CII: $239 \mathrm{mg} / \mathrm{dL}(15-40)$. Insulin antibodies were negative, antiGAD $21.5 \mathrm{mg} / \mathrm{Dl} \mathrm{U} / \mathrm{mL}(0-1)$, and anti-tyrosine phosphatasa $2.72 \mathrm{U} / \mathrm{mL}$. Glycemia were well controlled with subcutaneous insulin regimen (23 U Lantus and Humalog 4-3-5 U), with $\mathrm{HbAlc} 7.9 \%$, and negative glucosuria and ketonuria.

\section{Pathophysiology and Discussion}

Hypertriglyceridemia may cause AP in up to $7 \%$ of cases. This is the most common cause of acute biliary AP after alcohol [1, 6, 7]; however, it rarely occurs except when triglyceride levels exceed $1500 \mathrm{mg} / \mathrm{dL}$ [6, 7]. Nevertheless, the detection of mild to moderately elevated levels of triglycerides $(200-1000 \mathrm{mg} / \mathrm{dL})$ usually occurs in the early stages of the AP of any etiology; that is, the HTG can develop in the context of endocrine dysfunction that accompanies the $\mathrm{AP}$, or it may be the precipitating cause of it [6].

On the other hand, such high levels of triglycerides may indicate some sort of defect in lipid metabolism, a hypothesis that has been confirmed by several works that have found abnormalities or deficiencies of key enzymes in triglyceride metabolism, as example, mutations in the gene for lipoprotein lipase enzyme (LPL) located on chromosome $8[1,6,8]$.

The enzyme LPL is expressed in capillary endothelium of muscle and adipose tissue and is responsible for hydrolyzing triglycerides, releasing fatty acids [2], which will be captured and "internalized" by the cells. An altered or decreased activity of LPL may lead to an increase in circulating triglycerides. On the other hand, it has been observed that to reach levels high enough to develop clinically relevant 
complications, a condition that also affects the general metabolism [1] and acts as a trigger (diabetes mellitus, alcoholism, pregnancy, hypothyroidism, or certain drugs such as estrogens, furosemide, isotretinoin, tamoxifen, and $\beta$ blockers) has to coexist [2]. It is estimated that $75 \%$ of patients with pancreatitis due to hypertriglyceridemia have alcoholism or diabetes mellitus poorly controlled $[9,10]$.

Isolated cases of PA due to hypertriglyceridemia have been reported and treated with plasma or lipoprotein apheresis with favorable response [2]. However, the recognition of a decreased activity of the LPL enzyme as a key factor in the development of SH $[2,9,10]$ has enabled the development of new therapeutic options, such as intravenous administration of insulin or heparin [1]. Both activate the LPL bound to endothelium. In addition, heparin mobilizes and releases the enzyme of the endothelium to plasma $[1,2]$. Insulin promotes the synthesis of LPL and stimulates the uptake of fatty acids released from triglyceride hydrolysis by LPL itself $[1,2]$.

Octreotide has also been used, a somatostatin analogue, because it uses its receptors in the pancreas, modulating pancreatic exocrine secretion [2].

In the case presented, triglyceride levels reached $10260 \mathrm{mg} / \mathrm{dL}$, with an amylase also high, and clinical manifestations compatible with AP, in the context of diabetic ketoacidosis. When initiating treatment with insulin we not only got a glycemic control, but there was also a dramatic reduction in the HTG to values considered safe (triglycerides $<500 \mathrm{mg} / \mathrm{dL}$ ) after 96 hours of admission. Therefore, after normalization of blood glucose and correction of ketosis, it was decided to continue with a continuous infusion of insulin from 0.5 to $1 \mathrm{IU} / \mathrm{kg} / \mathrm{h}$, achieving standardization practice triglyceride levels. While experience in pediatric patients is very limited and the presentation through $\mathrm{SH}$ is unusual, we believe that treatment with intravenous insulin is an alternative that is fast and secure.

\section{References}

[1] S. I. Gan, A. L. Edwards, C. J. Symonds, and P. L. Beck, "Hypertriglyceridemia-induced pancreatitis: a casebased review," World Journal of Gastroenterology, vol. 12, no. 44, pp. 7197-7202, 2006.

[2] B. A. Greenberg, H. D. Hamam, C. R. Powers, H. J. LeMar, and T. G. Oliver, "Novel therapy: insulin, heparin, and octreotide in the treatment of hypertriglyceridemia, dramatic results," Endocrinologist, vol. 18, no. 5, pp. 213-215, 2008.

[3] A. Monga, A. Arora, R. P. S. Makkar, and A. K. Gupta, "Hypertriglyceridemia-induced acute pancreatitis-treatment with heparin and insulin," Indian Journal of Gastroenterology, vol. 22, no. 3, pp. 102-103, 2003.

[4] N. Mikhail, K. Trivedi, C. Page, S. Wali, and D. Cope, "Treatment of severe hypertriglyceridemia in nondiabetic patients with insulin," American Journal of Emergency Medicine, vol. 23, no. 3, pp. 415-417, 2005.

[5] A. V. Kyriakidis, B. Raitsiou, A. Sakagianni et al., "Management of acute severe hyperlipidemic pancreatitis," Digestion, vol. 73, no. 4, pp. 259-264, 2006.

[6] J. L. Diaz-Rubio, A. Torre-Delgadillo, and G. Robles-Díaz, "Diabetes mellitus in acute pancreatitis," Revista de Gastroenterologia de Mexico, vol. 67, no. 4, pp. 271-284, 2002.
[7] T. McLaughlin, F. Abbasi, C. Lamendola, H. Yeni-Komshian, and G. Reaven, "Carbohydrate-induced hypertriglyceridemia: an insight into the link between plasma insulin and triglyceride concentrations," Journal of Clinical Endocrinology and Metabolism, vol. 85, no. 9, pp. 3085-3088, 2000.

[8] U. C. Broede and D. J. Rader, "Gene therapy for lipoprotein disorders," Expert Opinion on Biological Therapy, vol. 5, no. 8, pp. 1029-1038, 2005.

[9] H. Alagözlu, C. Mehmet, K. Tarkan, and Ü. Selahattin, "Heparin and insulin in the treatment of hypertriglyceridemiainduced severe acute pancreatitis," Digestive Diseases and Sciences, vol. 51, no. 5, pp. 931-933, 2006.

[10] D. Yadav and C. S. Pitchumoni, "Issues in hyperlipidemic pancreatitis," Journal of Clinical Gastroenterology, vol. 36, no. 1, pp. 54-62, 2003. 


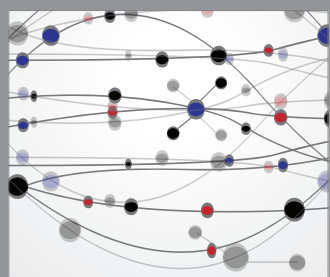

The Scientific World Journal
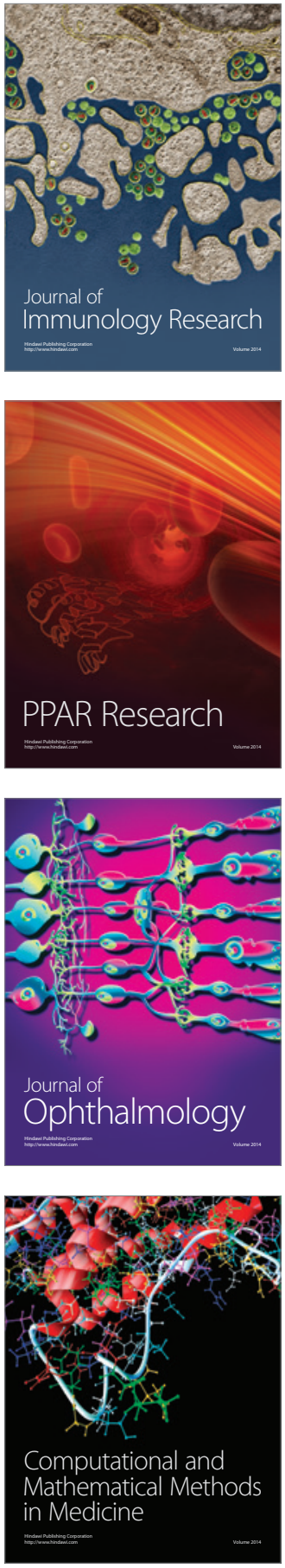

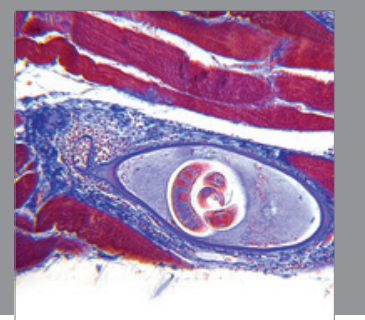

Gastroenterology

Research and Practice
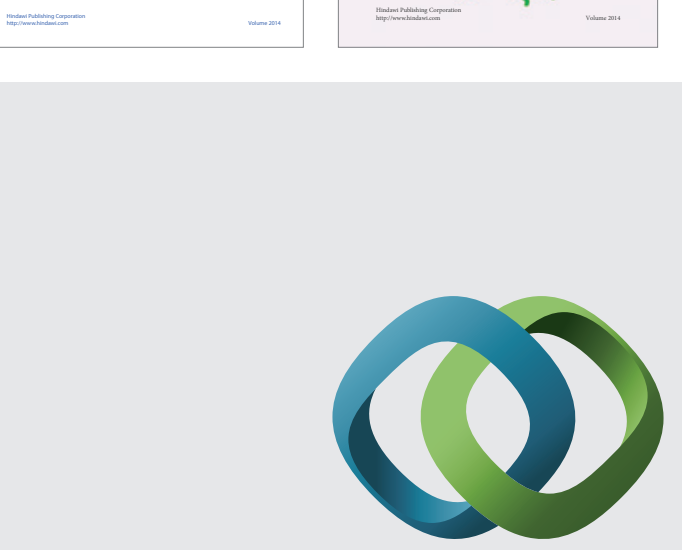

\section{Hindawi}

Submit your manuscripts at

http://www.hindawi.com
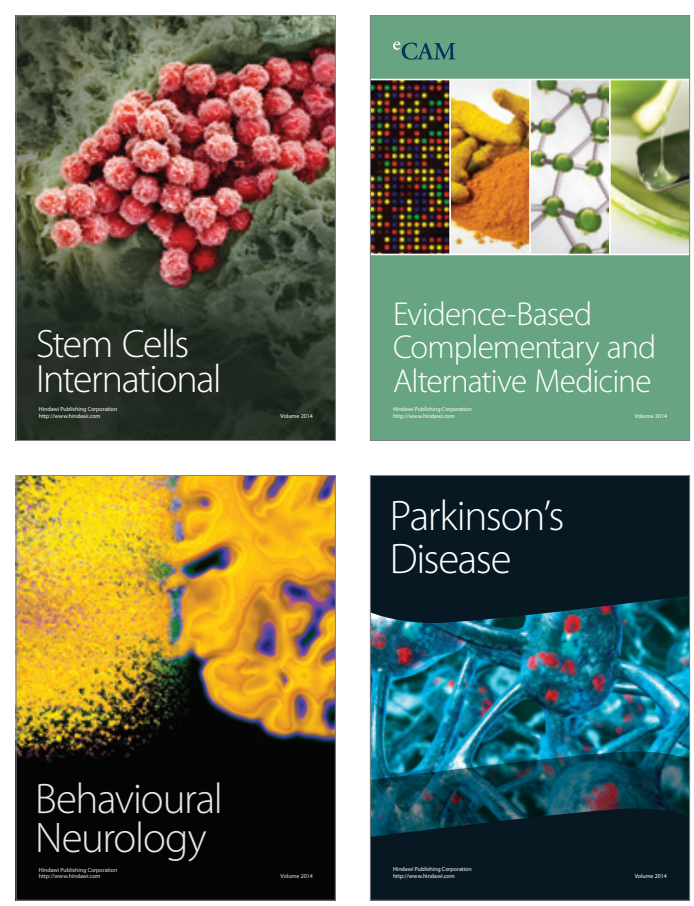

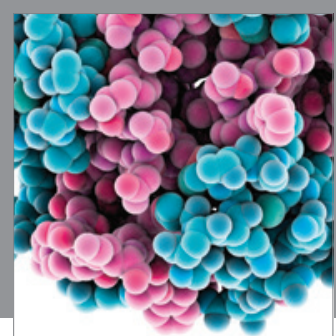

Journal of
Diabetes Research

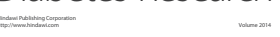

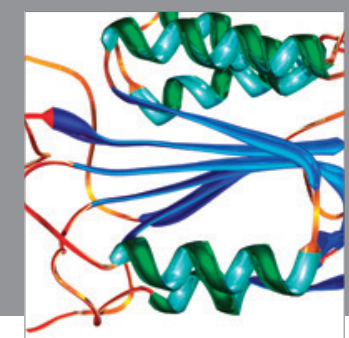

Disease Markers
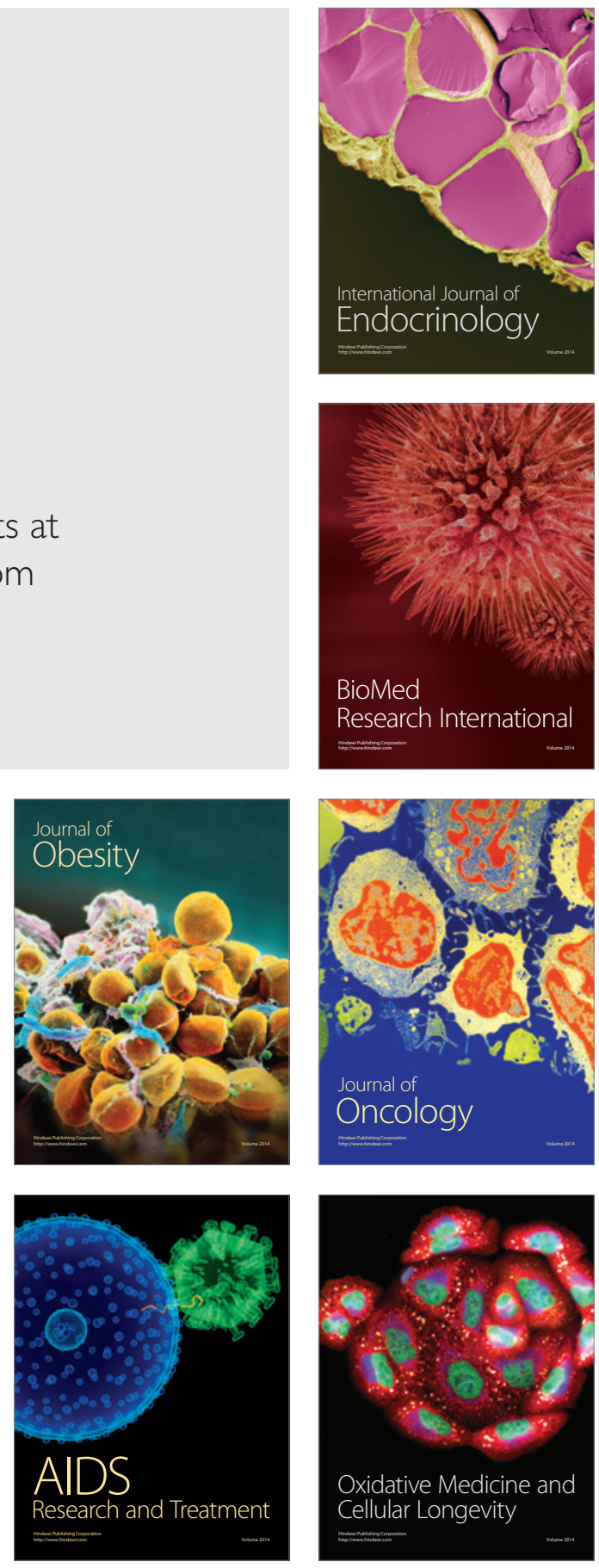